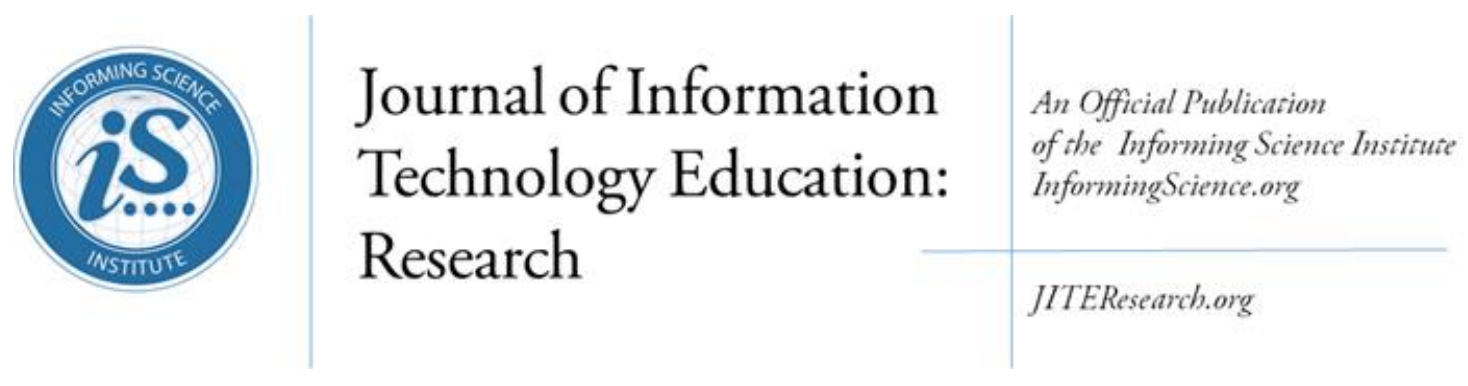

Volume 20, 2021

\title{
THE EFFECT OF Designing AND SEgMENTING INSTRUCTIONAL VIDEO
}

$\begin{array}{lll}\text { Penny Thompson } & \text { Oklahoma State University, Stillwater, OK, penny.thompson@,okstate.edu } \\ & \text { USA } \\ \text { Ying Xiu* } & \text { University of Illinois Urbana-Champaign, } & \text { yxiu@,illinois.edu } \\ & \text { Urbana, IL, USA } \\ \text { Jessica D. Tsotsoros } & \text { University of Oklahoma, Norman, OK, } & \text { jessica-tsotsoros@,ouhsc.edu } \\ \text { MSA } & \text { University of Central Oklahoma, } & \text { mrobertson5@uco.edu } \\ \text { Michelle A. Robertson } & \begin{array}{l}\text { Edmond, OK, USA } \\ \text { Corresponding author }\end{array}\end{array}$

ABSTRACT

Aim/Purpose

This study aims to explore whether instructors and educators should segment portions of instructional video that can be loaded and executed independently of other portions, and how long the segment portion of instructional video should be to effectively influence students' learning, perception, and interaction.

Background

Instructional videos are widely used in higher education for pedagogy purposes, and students expect their face-to-face and online courses to include video for effective instructional and learning outcomes. The literature indicates that researchers suggested that segmented video might assist learning and reduce cognitive burden; however, empirical research does not provide sufficient guidance about how to do it.

Methodology This mixed-methods study included quantitative data from an online experiment, followed by qualitative data from focus groups to help explain and expand on the quantitative findings. This study compared a 14-minute instructional video with the same content split into three segments, ranging from four to five minutes in length, to explore how segmenting affects students' learning and how students perceive and interact with the video. The quantitative portion of the study used an experimental design with random assignment to control and experimental groups. Participants were randomly assigned by Qualtrics to one of two conditions where they watched either a single long (14-minute) video (the control

Accepting Editor Felix O Quayson | Received: November 23, 2020 | Revised: March 19, April 22, 2021 | Accepted: April 27, 2021.

Cite as: Thompson, P., Xiu, Y., Tsotsoros, J. D., \& Robertson, M. A. (2021). The effect of designing and segmenting instructional video. Journal of Information Technology Education: Research, 20, 173-200. https://doi.org/10.28945/4756

(CC BY-NC 4.0) This article is licensed to you under a Creative Commons Attribution-NonCommercial 4.0 International License. When you copy and redistribute this paper in full or in part, you need to provide proper attribution to it to ensure that others can later locate this work (and to ensure that others do not accuse you of plagiarism). You may (and we encourage you to) adapt, remix, transform, and build upon the material for any non-commercial purposes. This license does not permit you to use this material for commercial purposes. 
Contribution

Findings

Recommendations for Practitioners

Recommendation for Researchers

Impact on Society

Future Research

Keywords group) or the same content split into three video segments (the experimental group). Participants in both groups were asked to watch the video(s), take a content knowledge quiz, and respond to an opinion questionnaire. The qualitative portion of the study consisted of focus groups where participants were asked to reflect on their overall perceptions of using online instructional video.

This study contributes to the literature knowledge on how students interact with instructional video and how, and if, longer instructional videos should be divided into shorter segments.

Results from this study indicated that there is no significant difference between the Long Video Group (control group) and the Segmented Video Group (experimental group) on measures of learning, interaction with or perceptions of the video. However, participants who engaged in multitasking activities other than texting performed worse on the learning measure. The focus group participants described a variety of behaviors and preferences for watching the instructional video but expressed a preference for videos that were about 20 minutes long.

For the purpose of building declarative knowledge, the number and length of instructional video segments may be less important than the other instructional materials and strategies instructors and educators provide to support students' interaction with the instructional video.

The qualitative findings suggest that while preferred instructional video length may differ based on context, a 20-minute instructional video may be preferred, or at least accepted, in a typical academic setting, though this possibility needs further study.

Results from this study may help instructors and educators to create high quality instructional video content by acknowledging that decisions about instructional video length and segmenting require professional discretion rather than arbitrary rules regarding video length.

Future researchers and practitioners can further evaluate and enhance the importance and design of instructional videos for pedagogical purposes, and additional research is needed before instructors, educators, and the educational field can accept the thought that any video over five or six minutes is considered too long for students' attention span.

instructional video, video segmenting, video length, multitasking; mixed methods

\section{INTRODUCTION}

Recent educational innovations such as MOOCs, blended learning, and the flipped classroom are introduced as new instructional systems and methods for teaching and learning and have brought a renewed focus on the use of video for pedagogical purposes. Instructional video is widely used in higher education (Carmichael et al., 2018; Johnson et al., 2014), and students have come to expect their face-to-face and online courses to include instructional video (Kaltura, 2019). When instructors and educators look for advice on how to create educational videos, they are likely to find two somewhat conflicting sets of instructions.

On one hand, the popular press discussions about "digital natives" continue to suggest that all students are savvy enough with technology to take advantage of digital instructional materials effectively without guidance, which is a mythical thinking that persists despite numerous challenges in the academic press (Corrin et al., 2018). On the other hand, it is commonly claimed that students have short 
attention spans and should not be expected to watch a video longer than four-to-six minutes (Guo et al., 2014; Hibbert, 2014; Myers, n.d; Vest, 2009). Thus, instructors and educators are encouraged to break content into segments based on arbitrary length limits rather than pedagogical considerations.

In an effort to provide guidance to instructors and educators regarding the optimal length for the instructional videos they create or curate, this mixed-methods study explored how university students interact with online instructional videos and whether breaking a longer video into segments affected their learning, interaction patterns, or perceptions of the video. This study's researchers conducted an online experimental study comparing a "long" video lasting 14 minutes with the same content split into three segments of four to five minutes each. The researchers anticipated that participants would have better recall of information presented in a series of four to five minute segments compared to a single long video with the same content. Also, the researchers expected that participants would like the segmented videos better and would report less multitasking while viewing the short videos. Likewise, because it is important to understand students' knowledge, skills, and current technology practices when deciding how to integrate technology into the learning environment (Corrin et al., 2018), this study's researchers used focus groups to gather qualitative rich, detailed information on students' preferences regarding segmented videos.

\section{Statement of THe Problem}

Empirical research does not yet provide sufficient guidance to instructors of online, hybrid, or flipped classrooms who face a decision about whether to segment instructional video and how long the segments should be. This guidance for instructors has been needed for some time but has become even more critical in the time of a global pandemic, especially when courses that were formerly offered in face-to-face settings were required to move online. The pressure to keep instructional video "short" may compete with the instructor's desire to create a complete, coherent lesson based on the content being taught. Furthermore, the time and effort involved in segmenting content into short video may be wasted if the shorter segments do not result in better learning (see Soicher \& Becker-Blease, 2020). Although video can pose a cognitive burden on the learner that is different from that posed by text, due to the richness of the media (Daft \& Lengel, 1986) and the transience of the medium (Spanjers et al., 2010; Wong et al., 2012), the few empirical studies supporting the common four-to-six minute recommendation were conducted in specialized contexts such as MOOCs (Guo et al., 2104) or professional education (Hibbert, 2014), and it is unknown whether recommendations from these contexts are generalizable to undergraduate learners in face-to-face, hybrid or online university courses. This research study seeks to advance understanding of video length and video segmenting for instructors at the university level and focuses on video designed to provide declarative knowledge rather than procedural knowledge.

\section{RESEARCH QUESTIONS}

This study addressed the following research questions:

1. How do students interact with an online instructional video featuring slides with narration?

2. Does breaking a long video into shorter segments influence how students perceive and interact with the instructional video?

3. Does breaking a long video into shorter segments affect student learning?

4. How do students explain their interactions with and preferences for instructional video? 


\section{LITERATURE REVIEW}

\section{USE OF INSTRUCTIONAL VIDEO}

An instructional video can take a variety of forms. Guo et al. (2014) defined the most common types of video used for instruction as (1) narrated slides, (2) narrated screen capture, (3) tablet drawing (e.g., Khan Academy videos), (4) classroom lecture capture, (5) studio produced (i.e., high production value video using a green screen), and (6) talking head video with the instructor sitting at his/her office desk speaking to the camera. Kay (2012) reviewed the literature on instructional video published between 2002 and 2011 and found that it presents both benefits and challenges. He found that students generally had positive attitudes about instructional video and thought it helped them learn (Kay, 2012). The video was shown to provide review material for examinations, allow more extensive note-taking than a real-time lecture, prepare students for class activities, and provide a way to make up material from a missed class (Kay, 2012). Students also appreciated having control over the time, place, and pace of learning (Kay, 2012). The challenges posed by the video included technical difficulties in playing the video and the inability for students to ask questions that arose while watching the video (Kay, 2012).

\section{COGNITIVE DEMANDS OF INSTRUCTIONAL VIDEO}

Based on what is known about human cognitive architecture, instructional video can be a doubleedged sword; it has the potential to enhance learning but also to overwhelm learners with too many simultaneous stimuli. In the Information Processing model of memory, Atkinson and Schiffrin (1968), using the computer as a metaphor, proposed a three-stage process. Information perceived through the five senses enters first through the sensory register, where it is either attended to or immediately lost. Information that gains a person's attention is then moved to short-term memory, also labeled working memory because this is where the intensive processing of the information begins. Short term memory has a limited duration of about 30 seconds (Atkinson and Schiffrin, 1968) and a limited capacity of about seven items (Miller, 1956). Information in working memory can be copied, or encoded, to long-term memory, where it can be retained indefinitely. Beyond merely memorizing, however, meaningful learning involves attending to the most relevant information, retrieving prior knowledge from long-term memory, manipulating new information and prior knowledge in working memory to make connections, and storing the new, integrated information back in long-term memory (Wittrock, 1974).

Cognitive Load Theory (Sweller, 1994; Sweller, 2010; Sweller et al., 1998) provides a more detailed picture of the limits of working memory by describing three types of cognitive load: intrinsic, extraneous, and germane. Intrinsic load is the cognitive burden caused by the inherent complexity of the information to be learned. Extraneous load occurs when elements of instruction demand learners' attention and processing capabilities but do not contribute to learning. This type of cognitive load is generally the result of instructional design errors. Germane load is the cognitive demand of information processing and is directly related to meaningful learning. These three types of cognitive load are additive; if the total cognitive load is beyond the learner's working memory capacity, learning cannot occur. Instructional designers should therefore seek to minimize extraneous cognitive load to maintain capacity for the more productive germane load.

The Cognitive Theory of Multimedia Learning (Mayer, 2005; Mayer \& Moreno, 2003) deals explicitly with how multimedia instructional materials should be designed to consider both the limits and the potential of human cognitive architecture. Mayer and Moreno (2003) outline three assumptions, grounded in extensive prior cognitive psychology research, that form the basis of the theory. First, they posit that cognitive processing takes place in two channels, "an auditory/verbal channel for processing auditory input and verbal representations and a visual/pictorial channel for processing visual 
input and pictorial representations" (p. 44). This description is a synthesis of the work of other researchers, including Paivio (1986) and Baddeley (1986), who proposed different but overlapping theories of dual channel processing. Second, they propose that each of these channels has limited processing capacity, based on Baddeley's (1986) work and Cognitive Load Theory (Chandler \& Sweller, 1991; Sweller, 1994). Finally, they state, based on the work of Wittrock (1974), that meaningful learning is a cognitively demanding task that requires "attending to important aspects of the presented material, mentally organizing it into a coherent cognitive structure, and integrating it with relevant existing knowledge" (p. 43).

Mayer and Moreno (2003) describe three different types of processing that can occur in each of the two processing channels. Essential processing refers to the cognitive processes "required for making sense of the presented material, such as...selecting words, selecting images, organizing words, organizing images, and integrating" (p. 45). Incidental processing refers to the processing of information that is extraneous to a task, such as background music. Finally, representational holding refers to holding information in short term memory. When the cumulative effort of these three types of processing exceeds learners' limited processing capacity, they experience cognitive overload, which inhibits learning. Mayer and Moreno (2003) advocate designing multimedia learning materials that reduce the cognitive burden on the learner by "redistributing essential processing, reducing incidental processing, or reducing representational holding" (p. 45). For example, the need to mentally integrate a diagram with on-screen text might place a heavy essential processing demand on the visual channel, but this problem can be alleviated by delivering the verbal material as an audio track instead of text. This change takes advantage of the benefits of dual channel processing while avoiding cognitive overload.

Instructional video that conforms to the design principles described by Mayer and Moreno (2003) can be beneficial for learning. Nevertheless, video can still pose a cognitive burden on the learner because of the richness (Daft \& Lengel, 1986) and transience of the medium. Video is a rich medium that includes sound, pictures, and movement. While a multi-channel presentation can help learn under the right circumstances, it also bears a risk of overloading the learner's working memory capacity by providing too many stimuli and therefore demanding too much essential processing. The transience of video requires representational holding and therefore increases its risk of imposing too much cognitive burden on the learner (Spanjers et al., 2010; Wong et al., 2012). Unlike static text and pictures on a printed page, narration and moving images (e.g., video) disappear quickly, and thus must be held in memory while new information is presented. Learners must shift attention back and forth between maintaining the new information in short term memory and processing it to make sense of it and encode it into long term memory. The transience of animations makes this difficult, and the faster the pace of the animation, the more difficult it becomes (Spanjers et al., 2010). While it is possible to pause and replay sections of the video, this cannot be done as quickly or easily as re-reading printed text or reviewing static images (Wong et al., 2012). Besides, the need to make decisions about when to pause the video adds another cognitive task. Using shorter segments may help mitigate the disadvantages of transient media (Spanjers et al., 2010; Wong et al., 2012).

Finally, learner behavior while watching a video can add to the cognitive burden. Students have difficulty staying focused on a class lecture in face-to-face environments, especially with long lectures (Farley et al., 2013), and boredom can be a trigger for student multitasking with communication technologies such as smartphones (Olufadi, 2015). Multitasking refers to "the human attempt to do simultaneously as many things as possible, as quickly as possible, preferably marshaling the power of as many technologies as possible" (Rosen, 2008, p. 105). It is likely this tendency to lose focus and turn to multitask is equally present when students watch a video in the privacy of their homes, without the social pressure to stay on task that a face-to-face classroom can present. Therefore, students watching instructional videos outside of class may be tempted to multitask with other media (e.g., texting 
friends, engaging with social media sites, etc.), thus imposing an additional cognitive burden on themselves. A long video may be more likely than a short video to trigger this multitasking behavior, due to boredom or fatigue.

\section{SEGMENTING VIDEO TO REDUCE COGNITIVE BURDEN}

One possible way to reduce the cognitive burden imposed by instructional video without sacrificing pedagogical value and content is to segment the presentation into shorter sections, giving the learner time to process the content from one segment before the next segment is presented, and facilitating the learner's ability to take breaks when attention begins to wander. In a study where participants viewed multimedia presentations of how lightning forms, participants who were able to view the presentation in very short (approximately 10-second) segments performed better on a transfer test than those who viewed the entire presentation at once (Mayer \& Chandler, 2001), a result the authors attributed to reduced cognitive load. In an investigation of the use of classroom videos to model good teaching practices to pre-service teachers, Moreno (2007) found that splitting a 15-minute video into two- or three-minute segments improved students' retention of the good teaching practices modeled in the video while simultaneously reducing perceived cognitive load. Other studies have shown that video presented in short segments interspersed with narration or interactivity can reduce cognitive load and improve learning (Mayer et al., 1999; Mayer et al., 2003). These studies suggest that, at least for procedural knowledge, segmenting a long lesson into smaller units can reduce the cognitive burden placed on students and can lead to better learning.

While most studies of video segmenting have focused on procedural knowledge, Ibrahim et al. (2012) included the segmented video for building declarative knowledge, specifically the use of video to teach university students about the life cycle of insects. They found that students who viewed five video segments of approximately six minutes each performed better on tests of retention and transfer than students who viewed the same lesson as a single 30-minute video. The segmented video in that study, however, included other enhancements besides the segmenting, which also contributed to the improved learning.

The length of the video segments in the studies reviewed above varied greatly, from 10 seconds to about six minutes. Therefore, an optimal length of video segments has not yet been established. Guo et al. (2014) analyzed data available in a selection of MOOCs (e.g., which videos a user played, start and end times for video playback, number of times the video was paused and restarted, etc.) and found that the median amount of time students engaged with videos was six minutes. Clossen (2018) also found that university students preferred very short videos, averaging about 4:30 minutes. Some studies, however, have shown students were receptive to watching longer videos. A qualitative study by Harrison (2015) found that the majority (54\%) of participants preferred videos that were five to ten minutes long. Alpert and Hodkinson (2019) found that students preferred a length of about 20 minutes and were willing to watch videos up to 30 minutes long, though this study explored the use of videos in the classroom rather than online. Saurabh and Gautam (2019) analyzed data from their own proprietary educational YouTube channel and found that the most frequently-watched videos were those in the 10-15 minute range.

The segmenting of a video is controlled by the instructor, while the controls provided by most online video players, such as the ability to pause, fast-forward, or "scrub" back and forth in a video, allow learners to make their own segmenting decisions. However, learner controls are only beneficial if the learners use them, and this may not always be the case. Biard et al. (2018) compared segmented video with unsegmented video allowing learner control for learning procedural knowledge to novices in an occupational therapy course. They found that only slightly more than half of the participants who had access to the pause button actually used it, and those that did pause the video did so infrequently and briefly. In their study, learners in the segmented video condition performed better than the learner control conditions on a test of procedural knowledge. The authors suggest that the novice learners in this study may not have had the meta-cognitive awareness to know when and for how 
long they should pause the video, and therefore gained benefit from having these decisions scaffolded by the instructor via segmenting. Students' skills and strategies in the use of instructional video may be less developed than their skills in learning from text (List \& Ballenger, 2019).

While the literature summarized above suggests that segmented videos might assist learning, there may also be disadvantages to providing segmented videos. Merkt et al. (2018) found no significant difference in recall information, transfer, or self-reported cognitive load between university students viewing segmented versus non-segmented versions of a physics tutorial. Beatty et al. (2019) used data from a learning management system to observe the video watching behavior of university business school students in a flipped classroom and found that when videos were split into multiple segments, many students only watched the first segment. They observed "a clear trend in student video-viewing pattern of fewer students watching the 2nd, 3rd, and/or 4th parts of the video sequence" (p. 381). This behavior may be explained in part by the work of Doolittle et al. (2015), who found that students considered extensive video segmenting to be annoying, even when they felt it helped them learn.

Slemmons et al. (2018) performed a quasi-experimental study with middle school students in a flipped learning environment, where the control group watched longer videos (up to 23 minutes) while the experimental group watched the same content in segmented video (averaging under eight minutes per segment). They measured students' scores on a quiz given immediately after students viewed the video, and also pre- and post-test scores on the entire educational unit. Although there were no significant differences between groups on the quiz or the unit tests as a group, male students scored significantly higher unit test scores in the segmented video group compared to the long video group. The authors attributed this difference to the different developmental trajectories of male and female students in this age group. While the study (Slemmons et al., 2018) has some intriguing findings regarding the effects of video length, it differs from this current study in that it targets much younger students. In addition, because it used a quasi-experimental design with existing classes, the definitions of "long" and "short" video were not consistent within each group. The current study used an experimental design with random assignment to assess the effect of long versus segmented video for university students.

\section{RESEARCH METHODOLOGY}

This mixed-methods study included quantitative data from an online experiment, followed by qualitative data from focus groups to help explain and expand on the quantitative findings. The online experiment was conducted using a survey designed in Qualtrics. Students accessed the survey through a system sponsored by the college for connecting students to available research participation opportunities. Students who are required to participate in research as part of their coursework can use this system to sign up for studies and get participation credit while still maintaining their privacy. The quantitative portion of the study used an experimental design with random assignment to control and experimental groups. Participants were randomly assigned by Qualtrics to one of two conditions where they watched either a single long (14-minute) video (the control group) or the same content split into three video segments (the experimental group). Participants in both groups were asked to watch the video(s), take a content knowledge quiz, and respond to an opinion questionnaire. The qualitative portion of the study consisted of focus groups where participants were asked to reflect on their overall perceptions of using online instructional video. This study was done outside the context of a course or a learning management system (LMS). The video in this study's experiment was posted on YouTube and then embedded in a Qualtrics survey. The research participants were not enrolled in any courses taught by this study's authors. The focus of this study was on video length and segmenting of instructional video and is not closely tied to any one particular delivery platform. 


\section{PARTICIPANTS}

\section{Online experiment participants}

Participants in the online experiment were students taking education courses at a Midwestern university, who received one hour of research participation credit to meet course requirements. Of the 189 questionnaires submitted, 51 were removed because the participants quit in the middle completing the survey, and an additional 56 were removed because they spent less than 18 minutes completing the questionnaire. Although the questionnaire was mistakenly not set to track the time participants spent on each page, responses that were completed in less than 18 minutes were judged to be invalid since these participants were unlikely to have watched the full 14 minutes of video content. This process resulted in 82 valid questionnaires for analysis, 44 from the Long Video Group and 38 from the Segmented Video Group.

Participants submitting valid questionnaires included 38 males and 44 females, with a mean age of 21.77 years (range 18 - 40). The self-reported breakdown of ethnicity was $64 \%$ white, $12 \%$ Native American, 7\% African American, 7\% Hispanic or Latino, 5\% multi-ethnic, and 5\% split between other ethnicities. Ninety-two percent of participants were undergraduates and eight percent were graduate students. Forty-eight percent were education majors, while the remaining 52 percent were divided between several majors, including agriculture, arts and sciences, business, engineering, and social science fields. A comparison with enrollment statistics available from the university registrar indicated that, compared to the total student population, the sample in this study had a slightly higher percentage of Native American, African American, and Hispanic/Latino students and a slightly lower percentage who identified as multiracial. The roughly equal split between males and females is representative of the general student population.

\section{Focus group participants}

Participants for the focus groups were initially recruited from those who completed the online questionnaire and voluntarily provided contact information. Of the 25 participants who provided contact information, three (all female and pursuing master's degrees) agreed to participate in focus groups.

To gain perspectives from undergraduate as well as graduate students, the researchers recruited additional focus group participants outside of the initial survey sample. Because the goal of the focus groups was to gain additional information on students' perceptions of instructional video in general, rather than specifically on their experience with the video provided in the online experiment, students from outside the initial sample would have insights to share, provided they had some experience with instructional video of varying length. Participants were recruited from an introductory honors biology class that was taught in "flipped" style, with required video lectures for students to watch outside of class to prepare for discussions and activities during class time. These students also had some experience with segmented video, as their instructor provided a segmented option for a small selection of their 45-minute lecture videos. The researchers randomly selected students from the class roster and invited them by email. Five females and one male from the biology class agreed to participate. Therefore, a total of nine students (six undergraduates and three graduates) participated in focus group meetings. All focus group participants received gift certificates to a popular online bookstore in the amount of 10 US dollars.

\section{MATERIALS}

The online video lectures, created by the first author, were narrated slide presentations centered on "myths and controversies in educational psychology." The lecture covered two topics where students commonly have misconceptions (Dale's Cone of Experience, VAK Learning Styles) and a third topic providing evidence-based theories of multimedia instruction as an alternative to the myths. This topic was chosen because it is a valuable topic for students in an education program to learn but is 
not always covered explicitly in their regular coursework. Therefore, the videos allowed an opportunity to provide students with valuable new content and then test their learning. In producing the video, the authors made an effort to follow Mayer's (2005) principles for multimedia design by featuring meaningful graphics explained by audio narration (see Figure 1).

\section{People (supposedly) remember:}

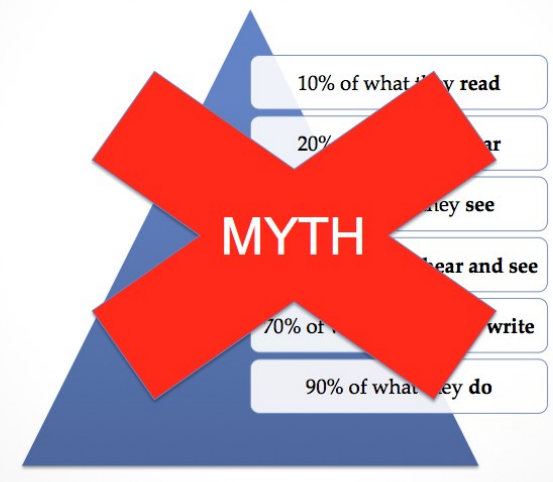

Figure 1. Screenshot of the instructional video

Parts of the lesson, however, did not lend themselves well to a graphical representation. In these cases, the presentation followed the common practice of including bulleted text on the screen (see Figure 2), with a voice narration that elaborated on the text. Thus, the text and audio narration was not redundant; the slides contained abridged versions of the audio narration. While redundant onscreen and audio texts have been shown to suppress learning (Mayer, 2005), on-screen text representing an abbreviated version of the spoken text has been shown in some cases to facilitate learning when no other visual information is presented (Adesope \& Nesbit, 2012; Moreno \& Mayer, 2005; Yue et al., 2013).

\section{Cognitive Theory of Multimedia Learning (Richard Mayer)}

- Research-based guidelines for optimal use of pictures, audio, and text to help people learn.

- "Satisfies our practical goal of developing principles for multimedia design based on theory-based research rather than the intuitions of designers" (Mayer, 2002, p. 134). $\bullet$

Figure 2. Screenshot of instructional video screen with text

Two versions of the video were produced. The first version was a single 14-minute lecture. For the second version, the same 14-minute lecture was edited using iMovie and split into three lectures of 
four or five minutes each. The videos were uploaded to YouTube and embedded in the online questionnaire created using Qualtrics.

\section{MEASURES}

The online questionnaire, developed by the authors, consisted of the embedded videos, an 11-question content knowledge quiz (Appendix A), and an opinion questionnaire consisting of Likert-type questions and one open-ended question (Appendix B). The content knowledge quiz was designed in multiple-choice format to assess participants' basic recall and understanding of the concepts presented in the video. Three or four questions were created to test knowledge on each of the three topics in the video (Dale's Cone of Experience, Learning Styles, and evidence-based theories of learning with media). The correct answer for each question reflected points that were made clear in the video, while the incorrect choices reflected common student misunderstandings about the topic, based on the first author's previous experience teaching introductory educational psychology classes. Participants received one point for each correct answer, for a total possible score of 11 .

The remaining questions sought to understand how participants used the video and their opinion of it. Questions about video use were developed by listing the features of the video, such as the ability to replay, pause, and scrub forward and backward, and asking participants to report how many times they used these features. The means were computed for each of these behaviors to facilitate comparing between Long Video and Segmented Video groups. Opinion questions and demographic questions were also written by the researchers. This portion of the questionnaire asked participants to report on how they used the videos, how they liked the videos, and whether they thought the videos enhanced their learning. A five-point Likert-type scale was used for the opinion questions, and comparisons between groups were made on each question.

Two authors (one faculty member and one doctoral student in an educational technology program) developed the quiz and questionnaire, discussing each question until each agreed that the question was clearly worded and relevant to the construct being measured. The questionnaire was then submitted to the remaining two authors (two educational technology doctoral students with extensive teaching and instructional design experience) for additional feedback and discussion, once again reaching a consensus on clarity and construct validity.

Due to the brevity of the intervention, no pretest was given. The omission of a pretest is appropriate when there is reason to believe the pretest itself might affect the results (Gall et al., 2007). In this study, there was a risk that participants would gain some content knowledge simply by taking a pretest, which would confound the measure of what they learned from the video.

\section{PROCEDURES}

After clicking a link provided in an email, participants were randomly assigned (using a survey flow feature available in the Qualtrics software) to one of two groups. The Long Video Group (control group) viewed a 14-minute video lecture, and the Segmented Video Group (experimental group) viewed the same lecture broken into three segments. All participants were then presented with the content knowledge quiz and opinion questions.

Participants in both groups were instructed to spend as much time with the video(s) as they needed to learn the material before proceeding to the quiz. The video controls were available so participants could pause, replay, or skip ahead. Once they advanced to the next page, however, they were not allowed to return to the video page. Quiz and opinion questions were identical for both groups, and the quiz questions were presented in random order by the Qualtrics software.

Participants who agreed to participate in focus groups met with the researchers in a meeting room on campus at a mutually agreeable time. Separate meetings were held for participants recruited through the survey and those recruited from the biology class. The group size was determined by participant 
availability, resulting in three focus groups with three participants each and one interview with a single participant. While three-person focus groups are not ideal because they may prompt less discussion than would occur with a larger group, they can still be effective (Gill et al., 2008). The meetings were audio recorded. Each meeting began with the first author asking a pre-planned set of openended questions (e.g., "How do you watch the video? Do you pause, replay, take notes, etc.?"), but all members of the research team posed follow-up questions based on what the participants had discussed in response to the primary questions.

\section{DATA ANALYSIS}

The data sources consisted of the timestamp from Qualtrics indicating how much time participants spent accessing the questionnaire, the content knowledge quiz, the opinion questions, and transcripts from the focus groups.

Quantitative data from the questionnaire were analyzed with descriptive statistics and with t-tests to look for differences by video condition on quiz scores, manner of interacting with the video, and opinion of the video. A t-test was also conducted to compare quiz scores between participants who reported multitasking during the video and those who did not. The open-ended question was analyzed for recurring common words or phrases (e.g., "can’t ask questions," "don't like video," etc.).

Focus group interviews were audio-recorded and transcribed in their entirety. The researchers met to read the transcripts together to become familiar with them. The group then selected one focus group transcript and performed an inductive coding (Corbin \& Strauss, 2008) process to identify common themes. The unit of analysis was a complete thought, which was generally two to three spoken sentences. In general, one code per unit was assigned, but in a few cases, the research team agreed that a unit addressed two codes simultaneously. This initial coding produced a preliminary codebook, which was used to jointly code the remaining three transcripts, with codes added and adjusted as needed. The team then discussed and categorized the codes into larger themes, adjusting the original coding as the categories evolved. A Ph.D. student not involved with the project then used the final codebook to code all four transcripts so inter-rater reliability could be computed. In cases where more than one code was assigned to a unit, a match was recorded if there was agreement on at least one code. The agreement between the group and the outside coder was 73\% at the code level and $78 \%$ at the category level.

\section{FINDINGS}

The findings are presented below in the context of the research questions.

\section{RQ1: HOW DO STUDENTS INTERACT WITH AN ONLINE INSTRUCTIONAL VIDEO PRESENTATION?}

Of the 82 valid surveys analyzed, 44 were from the Long Video Group and 38 from the Segmented Video Group. Participants overall earned an average quiz score of $5.26(\mathrm{SD}=2.61)$ out of a possible 11 points. Participants' opinions about the video are summarized in Table 1.

Sixty-seven percent of respondents agreed to some degree with the statement "I learned a lot from this video" and $68 \%$ at least somewhat agreed that "the length of the video lesson was just right for helping me learn," but only 54\% reported that they generally liked learning from video. 
Effect of Segmenting Instructional Videos

Table 1: Opinions of video lesson (in percentages of respondents with highest one bolded)

\begin{tabular}{|c|c|c|c|c|c|c|c|}
\hline & $\begin{array}{l}\text { Strongly } \\
\text { Disagree }\end{array}$ & Disagree & $\begin{array}{l}\text { Somewhat } \\
\text { Disagree }\end{array}$ & Uncertain & $\begin{array}{c}\text { Somewhat } \\
\text { Agree }\end{array}$ & Agree & $\begin{array}{c}\text { Strongly } \\
\text { Agree }\end{array}$ \\
\hline $\begin{array}{l}\text { I learned a lot from the video } \\
\text { lesson. }\end{array}$ & 2.4 & 12.2 & 9.8 & 8.5 & 39.0 & 26.8 & 1.2 \\
\hline Long Video Group & 2.3 & 9.1 & 13.6 & 11.4 & 38.6 & 22.7 & 2.3 \\
\hline Segmented Video Group & 2.6 & 15.8 & 5.3 & 5.3 & 39.5 & 31.6 & 0 \\
\hline $\begin{array}{l}\text { The voice narration in the video } \\
\text { lesson helped me learn. }\end{array}$ & 13.4 & 9.8 & 15.9 & 14.6 & 19.5 & 22.0 & 4.9 \\
\hline Long Video Group & 13.6 & 9.1 & 22.7 & 11.4 & 15.9 & 20.5 & 6.8 \\
\hline Segmented Video Group & 13.2 & 10.5 & 7.9 & 18.4 & 23.7 & 23.7 & 2.6 \\
\hline $\begin{array}{l}\text { The images in the video lesson } \\
\text { helped me learn. }\end{array}$ & 9.8 & 11.0 & 7.3 & 13.4 & 30.5 & 22.0 & 6.1 \\
\hline Long Video Group & 9.1 & 9.1 & 9.1 & 20.5 & 31.8 & 11.4 & 9.1 \\
\hline Segmented Video Group & 10.5 & 13.2 & 5.3 & 5.3 & 28.9 & 34.2 & 2.6 \\
\hline $\begin{array}{l}\text { In general, I like learning from } \\
\text { video }\end{array}$ & 6.1 & 14.6 & 18.3 & 7.3 & 28.0 & 20.7 & 4.9 \\
\hline Long Video Group & 2.3 & 13.6 & 20.5 & 4.5 & 36.4 & 18.2 & 4.5 \\
\hline Segmented Video Group & 10.5 & 15.8 & 15.8 & 10.5 & 18.4 & 23.7 & 5.3 \\
\hline $\begin{array}{l}\text { The length of the video lesson } \\
\text { was just right for helping me } \\
\text { learn. }\end{array}$ & 4.9 & 8.6 & 12.3 & 6.2 & 24.7 & 28.4 & 14.8 \\
\hline Long Video Group & 6.8 & 9.1 & 13.6 & 6.8 & 27.3 & 22.7 & 13.6 \\
\hline Segmented Video Group & 2.7 & 8.1 & 10.8 & 5.4 & 21.6 & 35.1 & 16.2 \\
\hline $\begin{array}{l}\text { The video lesson was interesting } \\
\text { to me. }\end{array}$ & 12.2 & 11.0 & 14.6 & 8.5 & 32.9 & 19.5 & 1.2 \\
\hline Long Video Group & 11.4 & 11.4 & 13.6 & 9.1 & 34.1 & 18.2 & 2.3 \\
\hline Segmented Video Group & 13.2 & 10.5 & 15.8 & 7.9 & 31.6 & 21.1 & 0 \\
\hline $\begin{array}{l}\text { In general, I think I learn more } \\
\text { from video lessons like this one } \\
\text { than I do from face-to-face lec- } \\
\text { tures }\end{array}$ & 16.0 & 24.7 & 11.1 & 17.3 & 17.3 & 11.1 & 2.5 \\
\hline Long Video Group & 6.8 & 27.3 & 9.1 & 20.5 & 22.7 & 9.1 & 4.5 \\
\hline Segmented Video Group & 27.0 & 21.6 & 13.5 & 13.5 & 10.8 & 13.5 & 0 \\
\hline $\begin{array}{l}\text { The video lesson was challeng- } \\
\text { ing but not too difficult for me. }\end{array}$ & 3.7 & 7.3 & 19.5 & 13.4 & 42.7 & 11.0 & 2.4 \\
\hline Long Video Group & 2.3 & 9.1 & 22.7 & 6.8 & 45.5 & 11.4 & 2.3 \\
\hline Segmented Video Group & 5.3 & 5.3 & 15.8 & 21.1 & 39.5 & 10.5 & 2.6 \\
\hline $\begin{array}{l}\text { The video lesson was useful to } \\
\text { me. }\end{array}$ & 2.5 & 7.4 & 14.8 & 13.6 & 35.8 & 21.0 & 4.9 \\
\hline Long Video Group & 2.3 & 4.5 & 18.2 & 11.4 & 38.6 & 15.9 & 9.1 \\
\hline Segmented Video Group & 2.7 & 10.8 & 10.8 & 16.2 & 32.4 & 27.0 & 0 \\
\hline $\begin{array}{l}\text { The video lesson was clear and } \\
\text { easy to understand. }\end{array}$ & 0 & 2.5 & 4.9 & 11.1 & 32.1 & 30.9 & 18.5 \\
\hline Long Video Group & 0 & 2.3 & 4.7 & 11.6 & 46.5 & 25.6 & 9.3 \\
\hline Segmented Video Group & 0 & 2.6 & 5.3 & 10.5 & 15.8 & 36.8 & 28.9 \\
\hline
\end{tabular}




\begin{tabular}{|c|c|c|c|c|c|c|c|}
\hline & $\begin{array}{l}\text { Strongly } \\
\text { Disagree }\end{array}$ & Disagree & $\begin{array}{l}\text { Somewhat } \\
\text { Disagree }\end{array}$ & Uncertain & $\begin{array}{c}\text { Somewhat } \\
\text { Agree }\end{array}$ & Agree & $\begin{array}{c}\text { Strongly } \\
\text { Agree }\end{array}$ \\
\hline $\begin{array}{l}\text { The video lesson was too easy } \\
\text { for me. }\end{array}$ & 4.9 & 17.1 & 34.1 & 18.3 & 17.1 & 4.9 & 3.7 \\
\hline Long Video Group & 4.5 & 25.0 & 25.0 & 20.5 & 15.9 & 4.5 & 4.5 \\
\hline Segmented Video Group & 5.3 & 7.9 & 44.7 & 15.8 & 18.4 & 5.2 & 2.6 \\
\hline $\begin{array}{l}\text { In general, I think video lessons } \\
\text { like this one and face-to-face } \\
\text { lectures are about equal when it } \\
\text { comes to helping me learn. }\end{array}$ & 9.8 & 18.3 & 20.7 & 14.6 & 15.9 & 15.9 & 4.9 \\
\hline Long Video Group & 9.1 & 13.6 & 13.6 & 20.5 & 22.7 & 15.9 & 4.5 \\
\hline Segmented Video Group & 10.5 & 23.7 & 28.9 & 7.9 & 7.9 & 15.8 & 5.3 \\
\hline
\end{tabular}

Half of the participants reported that they replayed a portion of the video at least once, while only $24 \%$ paused the video to take notes. Table 2 provides more detail on the participants' reported video watching behavior.

Table 2: Video watching behaviors (in percentages of respondents with highest one bolded)

\begin{tabular}{|c|c|c|c|c|c|}
\hline \multirow[t]{2}{*}{ Watching Behavior } & \multicolumn{5}{|c|}{ Percentage of Responses } \\
\hline & None & 1 to 3 & 4 to 6 & 8 to 10 & $\begin{array}{l}\text { More } \\
\text { than } 10\end{array}$ \\
\hline $\begin{array}{l}\text { Watched the video from beginning to end } \\
\text { without pausing or stopping }\end{array}$ & 17.1 & 78.0 & 2.4 & 1.2 & 1.2 \\
\hline Long Video Group & 18.2 & 75.0 & 2.3 & 2.3 & 2.3 \\
\hline Segmented Video Group & 15.8 & 81.6 & 2.6 & 0 & 0 \\
\hline Took a break for five or more minutes & 84.1 & 13.4 & 2.4 & 0 & 0 \\
\hline Long Video Group & 86.4 & 9.1 & 4.5 & 0 & 0 \\
\hline Segmented Video Group & 81.6 & 18.4 & 0 & 0 & 0 \\
\hline Took a break for less than five minutes & 68.3 & 29.3 & 1.2 & 1.2 & 0 \\
\hline Long Video Group & 75.0 & 20.5 & 2.3 & 2.3 & 0 \\
\hline Segmented Video Group & 60.5 & 39.5 & 0 & 0 & 0 \\
\hline Paused the video to take notes & 75.1 & 14.6 & 6.1 & 2.4 & 1.2 \\
\hline Long Video Group & 70.5 & 20.5 & 4.5 & 4.5 & 0 \\
\hline Segmented Video Group & 81.6 & 7.9 & 7.9 & 0 & 2.6 \\
\hline Replayed portions of the video & 50.6 & 42.0 & 3.7 & 2.5 & 1.2 \\
\hline Long Video Group & 54.5 & 36.4 & 4.5 & 2.3 & 2.3 \\
\hline Segmented Video Group & 45.9 & 48.6 & 2.7 & 2.7 & 0 \\
\hline Sent or replied to a text message & 50.0 & 37.8 & 8.5 & 1.2 & 2.4 \\
\hline Long Video Group & 40.9 & 47.7 & 6.8 & 0 & 4.5 \\
\hline Segmented Video Group & 60.5 & 26.3 & 10.5 & 2.6 & 0 \\
\hline $\begin{array}{l}\text { Multitasked on something other than text } \\
\text { messaging }\end{array}$ & 42.7 & 45.1 & 4.9 & 2.4 & 4.9 \\
\hline Long Video Group & 38.6 & 50.0 & 2.3 & 4.5 & 4.5 \\
\hline Segmented Video Group & 47.4 & 39.5 & 7.9 & 0 & 5.3 \\
\hline
\end{tabular}


Concerning multitasking, half of the participants sent or responded to text messages while viewing the video, and $57 \%$ did some type of multitasking other than texting (see Table 3 ).

Table 3: Multitasking activities other than texting

\begin{tabular}{|c|c|}
\hline Multitasking Activity & Percentage of Respondents \\
\hline $\begin{array}{l}\text { Used a social networking site (e.g., Facebook, } \\
\text { Twitter, SnapChat, etc.) }\end{array}$ & 26.8 \\
\hline Long Video Group & 22.7 \\
\hline Segmented Video Group & 31.6 \\
\hline Multitasked on something not listed & 18.3 \\
\hline Long Video Group & 15.9 \\
\hline Segmented Video Group & 21.1 \\
\hline Watched television & 11.0 \\
\hline Long Video Group & 15.9 \\
\hline Segmented Video Group & 5.3 \\
\hline Read another web page & 7.3 \\
\hline Long Video Group & 6.8 \\
\hline Segmented Video Group & 7.9 \\
\hline Did homework & 7.3 \\
\hline Long Video Group & 0 \\
\hline Segmented Video Group & 15.8 \\
\hline Talked on the phone & 3.7 \\
\hline Long Video Group & 6.8 \\
\hline Segmented Video Group & 0 \\
\hline Watched another video & 3.7 \\
\hline Long Video Group & 6.8 \\
\hline Segmented Video Group & 0 \\
\hline Played a video game & 2.4 \\
\hline Long Video Group & 2.3 \\
\hline Segmented Video Group & 2.6 \\
\hline Read a book or magazine & 0 \\
\hline Long Video Group & 0 \\
\hline Segmented Video Group & 0 \\
\hline Did not multitask & 42.7 \\
\hline Long Video Group & 40.9 \\
\hline Segmented Video Group & 44.7 \\
\hline
\end{tabular}

\section{RQ2: DOES BREAKING A LONG VIDEO INTO SHORTER SEGMENTS INFLUENCE HOW STUDENTS PERCEIVE AND INTERACT WITH THE INSTRUCTIONAL VIDEO?}

Independent samples t-tests were performed to explore differences between groups. There were no significant differences between the Long Video Group and Segmented Video Group on time spent watching the video, number of pauses and replays, ratings of the quality or length of the video, or self-reported instances of texting or other multitasking during the video (see Table 4). 
Table 4. Group differences for long video and segmented video conditions

\begin{tabular}{|c|c|c|c|c|c|c|}
\hline Variable & $\mathrm{N}$ & Mean & $\mathrm{SD}$ & $\mathrm{t}$ & $\mathrm{df}$ & $p$ \\
\hline Minutes spent in survey & & & & -1.74 & 77 & .087 \\
\hline Long Video Group & 43 & 30.09 & 8.77 & & & \\
\hline Segmented Video Group & 36 & 33.86 & 10.54 & & & \\
\hline Quiz scores & & & & -1.04 & 80 & .301 \\
\hline Long Video Group & 44 & 4.98 & 2.67 & & & \\
\hline Segmented Video Group & 38 & 5.58 & 2.54 & & & \\
\hline Quiz scores - males only & & & & .19 & 36 & .852 \\
\hline Long Video Group & 21 & 5.10 & 2.79 & & & \\
\hline Segmented Video Group & 17 & 4.94 & 2.14 & & & \\
\hline Quiz scores - females only & & & & -1.51 & 42 & .138 \\
\hline Long Video Group & 23 & 4.87 & 2.60 & & & \\
\hline Segmented Video Group & 21 & 6.10 & 2.77 & & & \\
\hline Number of pauses & & & & .50 & 80 & .621 \\
\hline Long Video Group & 44 & 1.43 & .79 & & & \\
\hline Segmented Video Group & 38 & 1.34 & .85 & & & \\
\hline Number of replays & & & & -.05 & 79 & .964 \\
\hline Long Video Group & 44 & 1.61 & .87 & & & \\
\hline Segmented Video Group & 37 & 1.62 & .68 & & & \\
\hline Rating of video quality & & & & .78 & 80 & .440 \\
\hline Long Video Group & 44 & 4.32 & 1.55 & & & \\
\hline Segmented Video Group & 38 & 4.03 & 1.85 & & & \\
\hline Rating of video length & & & & -1.14 & 79 & .257 \\
\hline Long Video Group & 44 & 4.61 & 1.79 & & & \\
\hline Segmented Video Group & 37 & 5.05 & 1.65 & & & \\
\hline Instances of texting & & & & 1.26 & 80 & .211 \\
\hline Long Video Group & 44 & 1.80 & .93 & & & \\
\hline Segmented Video Group & 38 & 1.55 & .80 & & & \\
\hline Instances of other multitasking & & & & .45 & 80 & .651 \\
\hline Long Video Group & 44 & 1.86 & 1.00 & & & \\
\hline Segmented Video Group & 38 & 1.76 & 1.00 & & & \\
\hline
\end{tabular}

In the open-ended question, several participants commented that they liked the video, found the topic interesting, or learned something new from the video. Four participants in the Long Video Group, however, mentioned that the video was too long (e.g., "I thought the information in the video was valuable, however, the length of the video was difficult to sit through"), while no one from the Segmented Video Group expressed dissatisfaction with the video length. One participant from the Long Video Group explicitly stated that a segmented video would have been more appealing:

I had mixed feelings about the video lesson. Overall all it wasn't bad. The graphics were fine and the narration was fine. The length of the video was too long though. Had it been several videos of shorter length I feel like I would have been more likely to go back and re-watch them. The thought of having to re-watch a 14-minute video seemed a little daunting to me.

In the Segmented Video Group, five participants specifically mentioned that they liked having the video split into segments. For example, one participant said: 
I liked that the lesson was broken down into small sections so that it wasn't one constant video. The whole lesson being broken down like that makes it to where you can replay the small clips multiple times or take breaks between the parts.

Another participant said:

The length was perfect for me. Had all three videos been combined into a $15 \mathrm{~min}+$ video I would have been much more likely to be distracted and preoccupied with other activities. However, because they were short I was able to focus and get through them quickly and not get bored.

Four participants (one in the Long Video Group and three in the Segmented Video Group) said they disliked learning from video in general. A participant in the Long Video Group said, "I feel like its [sic] harder to focus on online video lessons rather face-to-face lectures." A participant in the Segmented Video Group said, "I hate video lessons. They're impersonal and uninteresting." Seven participants in the Long Video Group and 11 in the Segmented Video Group complained about the quality of the specific video used in the study, commenting that the speaker's voice was "monotone."

\section{RQ3: DOES BREAKING A LONG VIDEO INTO SHORTER SEGMENTS AFFECT STUDENT LEARNING?}

An independent samples t-test was performed to measure any differences in quiz scores between the Long Video and Segmented Video groups. There was no significant difference between the Long Video and Segmented Video groups on the quiz score (see Table 4). To further explore this question, we divided the groups by gender and performed separate t-tests for males and females. There were no significant differences between the Long Video and the Segmented Video groups in either the males-only or the females-only groups.

Though incidental to the primary research questions, an independent samples t-test was also performed to compare participants, irrespective of video condition, who engaged in "multitasking other than texting" with those who did not, and this difference was significant. Participants who performed "multitasking other than texting" achieved significantly lower quiz scores $(\mathrm{M}=4.47, \mathrm{SD}=2.15)$ than those who did not perform these types of multitasking $(\mathrm{M}=6.31, \mathrm{SD}=2.83) ; \mathrm{t}(80)=3.36, \mathrm{p}=.001$.

\section{RQ4: HOW DO STUDENTS EXPLAIN THEIR INTERACTIONS WITH AND PREFERENCES FOR INSTRUCTIONAL VIDEOS?}

Focus groups were conducted about three months after the online survey was closed. Therefore, focus group participants were not asked specifically about the video used in the study but rather were asked to think about a situation where they had learned from the video, or, in the case of the biology students, to think about the videos they were required to watch for the biology class. With these examples in mind, participants discussed their typical manner of interacting with the instructional video and their preferences concerning it. Analysis of the focus group transcripts revealed five predominant themes: preferred length, minimizing clicks, different video watching behaviors, opinions of the instructional video, and multitasking. These themes are described below.

\section{Preferred length}

When asked about their preferred length for instructional video, some participants were quite precise in their answers, including one who declared without hesitation that the ideal length was "18 minutes." Others gave a range, such as "20-30 minutes." The overall consensus among participants was that the ideal video length was somewhere around 20 minutes. For example, one graduate student said, "I would say if it goes over about 20 minutes, I will start to check out a little bit." An undergraduate said "twenty minutes is, like, when...I have to get up and stretch and tell myself to focus again." 


\section{Minimizing clicks}

In contrast to the positive comments about segmented video seen in the questionnaire, several focus group participants stated that they did not like the repeated clicking required when watching a series of short videos. And they would prefer to decide for themselves when they needed to break up the video. One graduate student said, "I would rather have one video to watch, even if it was long. I would just stop it...If I had to leave for whatever reason I would just prefer that instead of having multiple files downloaded." An undergraduate student said, "I would like the consistency of the long video. I don't like to click and click more videos." Another undergraduate student expressed this sentiment more emphatically, saying, "I know how to use the pause button!"

\section{Video watching behaviors}

The questionnaire had revealed that $50 \%$ of the survey participants replayed a portion of the video and $24 \%$ paused the video to take notes. In the focus groups, one graduate student explained, "I usually watch it all the way through, and then I will rewind and go back to the parts that I did not understand or that I am kinda' fuzzy on still. I usually don't take notes on them." Another graduate student, however, reported that she would "definitely for sure take notes, especially if it's [video of the instructor] writing on the board."

Unlike the graduate student participants, the undergraduate participants from the biology class were required to complete worksheets (which they called "question packets") with questions about the video content. Thus, their watching behaviors were partially dictated by the requirements of the course. As one undergraduate student explained, "At the beginning of the semester I would try to watch the thing all the way through and then fill out the question packets, and I would realize that I had missed stuff and then I would have to go find it. So I think after I figured that out the hard way I would...pause [the video], fill [the packet] out, and then play a little more and fill out the questions." None of the focus group participants reported watching videos straight through without replaying.

\section{Opinions of instructional video}

Students expressed both positive and negative opinions of instructional video and discussed both online and in-class use of video. For example, one graduate student said, "I do think incorporating more videos into classrooms would be useful; it's a way to kind of help break up the monotony of the lecture." This participant also acknowledged some of the affordances of the video medium, saying,

You can do in a video what you can't necessarily do in, um, a face to face classroom, so you can edit the video, um, to show interesting things you can't necessarily do in the classroom. I'm thinking specifically like a demonstration of maybe a science experiment, maybe it's a little too dangerous to have in front of the students but you could show it through visual media.

At the same time, frustration with the lack of student-instructor interaction was a recurring theme in the focus group discussions. One undergraduate student said, "I think the biggest downfall of the videos is that there is no one to ask questions to at that moment." A graduate student also reported she found the video to be "less interactive, so you can't just ask the professor questions and get an answer right then, you know? It's not raise your hand and talk to them."

One undergraduate from the flipped biology class, who said she had a "love-hate" relationship with the videos, hinted at how engagement with the video might facilitate learning. As she described, "If I do watch the video and then I don't understand it, then I get to class and I still don't understand it, then I go back and watch the video again, it might help me understand it better. Or let's say I didn't have time to watch the videos before class and I watch it after. I might understand it after that...Sometimes I feel like they don’t benefit [me] but sometimes I feel like they do." 


\section{Multitasking}

The undergraduate and graduate students discussed multitasking while watching the instructional video. The undergraduate students emphasized digital media multitasking, such as texting, checking email, and using social media websites such as Facebook while they watched videos. One undergraduate discussed the temptation of multitasking when she said "if you get a text or some kind of notification, like, it is kind of hard to not look at it when [your cell phone] is sitting right in front of you." Graduate students also briefly discussed digital media multitasking. For example, one student explained how the temptation to use Facebook while watching a video at home was greater for her than the temptation she experienced during a lecture: "things like Facebook may be more accessible and more distracting...in class, in-person classes, I usually take notes on my iPad...I don't go to Facebook during class."

In addition to digital media multitasking, the graduate students reported performing activities like cooking, getting ready for the day, or paying bills online while watching instructional videos. One graduate student described how she "had a computer in the bathroom while brushing my teeth...that would mean that I watch [the video] at the same time." Another participant said, "I also do things like make a meal at the same time I am listening." One participant mentioned attending to family responsibilities while watching the videos, saying "I have kids and sometimes I take a break and do things like opening cracker boxes."

Both undergraduate and graduate students acknowledged that their multitasking was not ideal for learning, but the graduate students felt that multitasking with digital media was more detrimental to their learning than activities such as cooking a meal. As one graduate student explained, "when you are on social media...those activities are more interactive than, say, cooking a meal I have cooked so many times that I could do it without thinking about it." Another graduate student agreed, saying that media multitasking "takes more mental energy... is more a divided attention, I feel like, compared to [when] I am just cooking a meal but it is not something complicated, and I've made it a million times, but I'm also listening to this lecture."

\section{DISCUSSION}

Findings are discussed within the context of the research questions, followed by implications for practice.

\section{RQ1: HOW DO STUDENTS INTERACT WITH AN ONLINE INSTRUCTIONAL VIDEO PRESENTATION?}

Overall, participants in the online experimental portion of the study showed relatively little interaction (e.g., pausing or replaying) with the video. It is possible that the research setting influenced this behavior, as students did not have a strong incentive to engage deeply with the video content. Incentives such as course credit and grades have been shown to increase homework completion (Cullen et al., 1975) and student performance (Radhakrishnan et al., 2009), but those incentives were lacking in the current study. If the behaviors reported in this study are anywhere close to typical, however, it suggests that students might not always make full use of the features of video, such as the ability to pause and replay, which could facilitate their learning. This finding is consistent with the findings of Biard et al. (2018), who found that university students did not take advantage of the available pause button despite being encouraged by the researchers to do so. The transience of the video increases cognitive load due to the representational holding (Mayer \& Moreno, 2003) required, and students who forego the pause button miss an opportunity to manage this cognitive load.

Corrin et al. (2018) caution against assuming that the technology practices students bring from their everyday lives will translate into effective learning strategies. Results from this study add support to Corrin et al.'s (2018) recommendation that instructors "actively seek to know the students better by acknowledging and exploring the diversity of their technology skills, knowledge, and dispositions 
without making assumptions based on their age" (p. 110). Students who are adept at using or creating video for entertainment purposes may still need scaffolding from the instructor to use it productively for learning.

\section{RQ2: DOES BREAKING A LONG VIDEO INTO SHORTER SEGMENTS INFLUENCE HOW STUDENTS PERCEIVE AND INTERACT WITH THE INSTRUCTIONAL VIDEO?}

This study found no significant differences in students' self-reported video watching behaviors (e.g., pausing, replaying, or note-taking) based on whether they viewed the long video or the segmented video. Besides, there were no significant differences in students' perceptions of the interest level or helpfulness of the video. Based on Guo et al. (2014), who found that six minutes was the average amount of time students engaged with video in a MOOC, the researchers expected participants to report a more favorable opinion of the segmented video compared to the 14-minute video, but this was not the case. This inconsistency could be due in part to the different contexts in which instructional video was studied. Since MOOCs are more popular for professional development than for academic study (Christiansen et al., 2013), participants in the Guo et al. (2014) study may have been seeking just-in-time learning to answer a question or solve a problem. Participants in the current study, in contrast, were asked to learn as much as they could from a video before taking a quiz on its content and to reflect on their typical use of instructional video in their university coursework. Students in an academic context may have different expectations of video length, and perhaps more patience with slightly longer videos.

\section{RQ3: DOES BREAKING A LONG VIDEO INTO SHORTER SEGMENTS AFFECT STUDENT LEARNING?}

The findings from this study did not provide any evidence that segmenting a 14-minute video affected student learning. Participants in both groups scored low on the content knowledge quiz, and there was no significant difference between the two groups. Breaking longer video into shorter segments could potentially produce better learning by essentially forcing the learner to pause, thus reducing the amount of representational holding (Mayer \& Moreno, 2003) required, but the current study did not find evidence to support that effect with four- to five-minute segments.

An incidental finding, outside the original research question, was that multitasking while watching the video did affect student learning, and the effect was different for different types of multitasking. Participants who engaged in multitasking other than texting (predominantly use of social networking sites) had lower scores on the content knowledge quiz than those who did not perform this type of multitasking. Junco (2012) found that time spent on Facebook was more detrimental to student academic performance than merely checking the site. A text message can be sent quickly while social network sites encourage sustained involvement. The findings from this study are therefore consistent with the findings of Junco (2012), as well as with other studies (Bowman et al., 2010; Cho et al., 2015) that found no detrimental effect on learning when students multitasked with texting or instant messaging (though the study by Bowman et al., 2010, did find a detrimental effect on efficient use of study time). The multitaskers in the current study who engaged with social media while attempting to learn from the video essentially created a source of extraneous cognitive load (Sweller, 1994; Sweller, 2010; Sweller et al., 1998), making it more difficult for them to learn from the video.

\section{RQ4: HOW DO STUDENTS EXPLAIN THEIR INTERACTIONS WITH AND PREFERENCES FOR INSTRUCTIONAL VIDEO?}

The two qualitative data sources (open-ended question and focus groups) revealed divergent opinions about the value of segmenting video, with comments on the questionnaire expressing appreciation for the segmented video while focus group participants preferred to watch a video with fewer clicks. 
Also, the focus group participants expressed a consensus that their preferred video length was approximately 20 minutes. It is possible that the "long" version video used in this study was not long enough to require segmenting of video designed to build declarative knowledge. This would also be a possible explanation for the non-significant findings in the quiz scores. A future study with a longer video, such as a 60 -minute lecture divided into 20 -minute segments, would provide additional information on the optimal length of video segments. In any case, the results of this study do not provide clear evidence that a 14-minute lecture video is so long as to require segmenting.

Interestingly, the graduate students in the focus groups reported different multitasking behaviors than the undergraduates. While the undergraduates described only digital media multitasking, the graduate students reported watching instructional videos during their morning routines or while cooking a meal. The primary reason for this difference is most likely the fact that the undergraduates in this study were reflecting on specific use of instructional video, where they were required to complete worksheets designed to direct their attention to the most important points in the video lecture. They reported that they were most likely to complete these worksheets while they were watching the video, pausing as needed to record an answer to a question. In contrast, the graduate students were reflecting on their typical behavior in courses where they had used video. Without any requirements to complete worksheets, they were free to move away from the computer and do other types of multitasking. Besides, the graduate students mentioned having children, so it is possible that they had more family responsibilities and were, therefore, more likely to multitask with activities such as preparing meals or caring for children.

Despite the differences in multitasking activities, both undergraduate and graduate students in the focus groups reported a preference for longer videos with "fewer clicks," in contrast to the commenters on the online questionnaire who appreciated the segmented video. It is easy to understand why longer videos would be convenient for a student who wanted to play the video while cooking a meal, as the graduate students in this study reported doing. The undergraduate students, however, were closer to the computer while completing their worksheets. However, since they reported pausing the video frequently to answer worksheet questions, they were already performing a de facto segmentation of the video, which might explain why the additional clicking on multiple videos seemed more burdensome to them. In contrast, the small number of favorable responses to segmented video reported by participants in the online survey reflected participants' interaction with video under experimental conditions, where they were asked to learn as much as possible from the video without the use of supplemental materials.

Segmenting a video serves to scaffold students' interaction by setting pre-determined pauses, which may not only reduce cognitive load but also prompt students to focus attention on the video. Shorter segments would discourage students from stepping away from the computer to perform household tasks, as reported by the graduate students in this study, but the worksheets used in the biology class served this same purpose without the need to segment the video. Segmenting might be appreciated in the absence of other supports (as in the experimental portion of this study), but become burdensome when combined with other study aids, such as worksheets. This suggests that instructors making decisions about whether to segment video might consider what other support they are providing or could provide. Additional research is needed to explore whether the use of supplemental study materials affects students' preferences for segmented video.

\section{IMPLICATIONS FOR PRACTICE}

The findings from this study suggest several ways instructors might help students use instructional video more effectively. First, they can emphasize the interactive features of digital video (such as the ability to pause and replay) and encourage students to use these features. Without explicit encouragement, some students might simply play the video once, thus completing the assigned task but missing an opportunity for deeper learning. Second, instructors can provide scaffolding, in the form of guid- 
ing questions, to help students focus on the important concepts in the videos, as was done in the biology class in this study. Finally, they can emphasize the importance of giving full attention to the video despite the temptation to multitask, particularly with social networking sites or other websites that encourage sustained engagement. This explicit instruction and support from the instructor may encourage students to engage deeply rather than superficially with the instructional video, and thus facilitate deeper learning. Helping students use instructional video productively may be a better use of an instructor's time and effort than segmenting video to meet an arbitrary limit on video length.

\section{LIMITATION AND FUTURE RESEARCH}

This study was limited by the nature of the online experimental design, which may not have reflected participants' typical study behaviors. One participant used the open-ended item on the questionnaire to explain, "I lose interest fast when it is not really for a class of my own. If it was for an actual grade I think it would have been very simple." The perception that the speaker's voice was monotone may have further suppressed engagement. A more natural setting where participants had more extrinsic motivation to engage with the video (e.g., course grades) may have resulted in better learning and quiz performance, which may, in turn, have revealed additional differences between groups.

Quantitative data in this study focused on one type of instructional video - a narrated slide presentation - and findings may not apply to other types of video, such as lecture capture, tablet drawing, or talking head. The lesson content in this study focused on declarative knowledge, and does not generalize to video designed to build procedural knowledge.

Findings from the qualitative component of the study are limited by the sampling method, which relied on participants voluntarily providing contact information. In addition, qualitative research uses small samples "selected precisely because the researcher wishes to understand the particular in-depth, not to find out what is generally true of many" (Merriam, 2002, p. 28). Findings from the focus groups, therefore, reflect the unique, context-bound experiences and perceptions of the individual participants, but cannot be generalized to all university students.

\section{CONCLUSION}

This study adds to the literature on how students interact with video and how, and if, longer videos should be divided into shorter segments. While the quantitative results of this study do not lead to firm conclusions, they may provide some reassurance for instructors who resist pressure to split their instructional videos into "short" segments regardless of other pedagogical considerations. The qualitative findings suggest that while preferred video length may differ based on context, a 20-minute video may be preferred, or at least accepted, in a typical academic setting, though this possibility needs further study. While clearly, a concise presentation will always be important in the design of the instructional video, additional research is needed before we can accept the common wisdom that any video over five or six minutes is "too long for students' attention spans." When designing video for building declarative knowledge, the number and length of video segments may be less important than the other instructional materials and strategies that instructors provide to support students' interaction with the video.

\section{COMPLIANCE WITH ETHICAL STANDARDS}

Disclosure of potential conflicts of interest: There is no known conflict of interest.

Ethical approval: All procedures performed in studies involving human participants were in accordance with the ethical standards of the institutional and/or national research committee and with the 1964 Helsinki declaration and its later amendments or comparable ethical standards.

Informed consent: All aspects of this study, including the informed consent process, were reviewed and improved by our university's Institutional Review Board. 


\section{REFERENCES}

Adesope, O. O., \& Nesbit, J. C. (2012). Verbal redundancy in multimedia learning environments: A meta-analysis. Journal of Educational Psychology, 104(1), 250-263. https://doi.org/10.1037/a0026147

Alpert, F., \& Hodkinson, C. S. (2019). Video use in lecture classes: Current practices, student perceptions and preferences. Education + Training. 61(1), 31-45. https://doi.org/10.1108/ET-12-2017-0185

Atkinson, R. C., \& Shiflrin, R. M. (1968). Human memory: A proposed system and its control processes. In K. Spence \& J. Spence (Eds.), Psychology of learning and motivation (Volume 2) (pp. 89-195). Elsevier. https://doi.org/10.1016/S0079-7421(08)60422-3

Baddeley, A. D. (1986). Working memory. Oxford University Press.

Beatty, B. J., Merchant, Z., \& Albert, M. (2019). Analysis of student use of video in a flipped classroom. TechTrends, 63(4), 376-385. https://doi.org/10.1007/s11528-017-0169-1

Biard, N., Cojean, S., \& Jamet, E. (2018). Effects of segmentation and pacing on procedural learning by video. Computers in Human Behavior, 89, 411-417. https://doi.org/10.1016/i.chb.2017.12.002

Bowman, L. L., Levine, L. E., Waite, B. M., \& Gendron, M. (2010). Can students really multitask? An experimental study of instant messaging while reading. Computers and Education, 54(4), 927-931. https://doi.org/10.1016/j.compedu.2009.09.024

Carmichael, M., Reid, A. K., \& Karpicke, J. D. (2018). Assessing the impact of educational video on student engagement, critical thinking and learning: The current state of play. A Sage White Paper. https://us.sagepub.com/sites/default/files/hevideolearning.pdf

Chandler, P., \& Sweller, J. (1991). Cognitive load theory and the format of instruction. Cognition and Instruction, 8(4), 293-332. https://doi.org/10.1207/s1532690xci0804 2

Cho, K. W., Altarriba, J., \& Popiel, M. (2015). Mental juggling: When does multitasking impair reading comprehension? The Journal of General Psychology, 142(2), 90-105. https://doi.org/10.1080/00221309.2014.1003029

Clossen, A. S. (2018). Trope or trap? Role-playing narratives and length in instructional video. Information Technology and Libraries, 37(1), 27-38. https://doi.org/10.6017/ital.v37i1.10046

Corbin, J., \& Strauss, A. (2008). Basics of qualitative research (3rd ed.). Sage Publications.

Corrin, L., Apps, T., Beckman, K., \& Bennett, S. (2018). The myth of the digital native and what it means for higher education. In A. Attrill-Smith, C. Fullwood, M. Keep, \& D. J. Kuss (Eds.), The Oxford bandbook of cyber-psychology (pp. 1-19). Oxford University Press. https://doi.org/10.1093/oxfordhb/9780198812746.013.7

Cullen, F. T., Jr., Cullen, J. B., Hayhow, V. L., Jr., \& Plouffe, J. T. (1975). The effects of the use of grades as an incentive. Journal of Educational Research, 68(7), 277-279. https://doi.org/10.1080/00220671.1975.10884770

Doolittle, P. E., Bryant, L. H., \& Chittum, J. R. (2015). Effects of degree of segmentation and learner disposition on multimedia learning. British Journal of Educational Technology, 46(6), 1333-1343.

https://doi.org/10.1111/bjet.12203

Daft, R. L., \& Lengel, R. H. (1986). Organizational information requirements, media richness and structural design. Management Science, 32(5), 554-571. https://doi.org/10.1287/mnsc.32.5.554

Farley, J., Risko, E. F., \& Kingstone, A. (2013). Everyday attention and lecture retention: The effects of time, fidgeting, and mind wandering. Frontiers in Psychology, 4(619), 1-9.

https://doi.org/10.3389/fpsyg.2013.00619

Gall, M. D., Gall, J. P., \& Borg, W. R. (2007). Educational research: An introduction. Allyn \& Bacon.

Gill, P., Stewart, K., Treasure, E., \& Chadwick, B. (2008). Methods of data collection in qualitative research: Interviews and focus groups. British Dental Journal, 204(6), 291-295. https://doi.org/10.1038/bdj.2008.192

Guo, P. J., Kim, J., \& Rubin, R. (2014, March). How video production affects student engagement: An empirical study of MOOC videos. In Proceedings of the First ACM Conference on Learning@ Scale (pp. 41-50). Atlanta Georgia, USA: ACM. https://doi.org/10.1145/2556325.2566239 
Harrison, D. J. (2015). Assessing experiences with online educational videos: Converting multiple constructed responses to quantifiable data. International Review of Research in Open and Distributed Learning, 16(1), 168-192. https://doi.org/10.19173/irrodl.v16i1.1998

Hibbert, M. (2014, April 07). What makes an online instructional video compelling? https://er.educause.edu/articles/2014/4/what-makes-an-online-instructional-video-compelling

Ibrahim, M., Antonenko, P. D., Greenwood, C. M., \& Wheeler, D. (2012). Effects of segmenting, signaling, and weeding on learning from educational video. Learning, Media and Technology, 37(3), 220-235. https://doi.org/10.1080/17439884.2011.585993

Johnson, L., Adams Becker, S., Estrada, V., \& Freeman, A. (2014). NMC Horizon report: 2014 bigher education edition. The New Media Consortium. https://cdc.qc.ca/pdf/2014-Horizon-Report-creative-commonscopy.pdf

Junco, R. (2012). Too much face and not enough books: The relationship between multiple indices of Facebook use and academic performance. Computers in Human Behavior, 28(1), 187-198. https://doi.org/10.1016/j.chb.2011.08.026

Kaltura (2019). State of video in education 2019. https:// corp.kaltura.com/resources/the-state-of-video-in-education-2019/

Kay, R. H. (2012). Exploring the use of video podcasts in education: A comprehensive review of the literature. Computers in Human Behavior, 28(3), 820-831. https://doi.org/10.1016/j.chb.2012.01.011

List, A., \& Ballenger, E. E. (2019). Comprehension across mediums: The case of text and video. Journal of Computing in Higher Education, 31(3), 514-535. https://doi.org/10.1007/s12528-018-09204-9

Mayer, R. E. (2005). Cognitive theory of multimedia learning. In R. E. Mayer (Ed.), The Cambridge bandbook of multimedia learning (pp. 31-48). Cambridge University Press. https://doi.org/10.1017/CBO9780511816819.004

Mayer, R. E., \& Chandler, P. (2001). When learning is just a click away: Does simple user interaction foster deeper understanding of multimedia messages? Journal of Educational Psychology, 93(2), 390-397. https://doi.org/10.1037/0022-0663.93.2.390

Mayer, R. E., Dow, G. T., \& Mayer, S. (2003). Multimedia learning in an interactive self-explaining environment: What works in the design of agent-based microworlds? Journal of Educational Psychology, 95(4), 806-812. https://doi.org/10.1037/0022-0663.95.4.806

Mayer, R. E., \& Moreno, R. (2003). Nine ways to reduce cognitive load in multimedia learning. Educational Psychologist, 38(1), 43-52. https://doi.org/10.1207/S15326985EP3801_6

Mayer, R. E., Moreno, R., Boire, M., \& Vagge, S. (1999). Maximizing constructivist learning from multimedia communications by minimizing cognitive load. Journal of Educational Psychology, 91(4), 638-643. https://doi.org/10.1037/0022-0663.91.4.638

Merkt, M., Ballmann, A., Felfeli, J., \& Schwan, S. (2018). Pauses in educational videos: Testing the transience explanation against the structuring explanation. Computers in Human Behavior, 89, 399-410. https://doi.org/10.1016/j.chb.2018.01.013

Merriam, S. B. (2002). Qualitative research in practice: Examples for discussion and analysis. Jossey-Bass.

Miller, G. A. (1956). The magical number seven, plus or minus two: Some limits on our capacity for processing information. Psychological Review, 63(2), 81-97. https://doi.org/10.1037/h0043158

Moreno, R. (2007). Optimizing learning from animations by minimizing cognitive load: Cognitive and affective consequences of signaling and segmentation methods. Applied Cognitive Psychology, 21(6), 765-781. https://doi.org/10.1002/acp.1348

Moreno, R., \& Mayer, R. E. (2003). Verbal redundancy in multimedia learning: When reading helps listening. Journal of Educational Psychology, 94(1), 156-163. https://doi.org/10.1037//0022-0663.94.1.156

Myers, S. (n.d.). 6 Tips for creating engaging video lectures that students will actually watch. https://teaching.temple.edu/edvice-exchange/2016/03/6-tips-creating-engaging-video-lectures-students-will-actually-watch 


\section{Effect of Segmenting Instructional Videos}

Olufadi, Y. (2015). A configurational approach to the investigation of the multiple paths to success of students through mobile phone use behaviors. Computers \& Education, 86, 84-104. https://doi.org/10.1016/j.compedu.2015.03.005

Paivio, A. (1986). Mental representations: A dual coding approach. Oxford University Press.

Radhakrishnan, P., Lam, D., \& Ho, G. (2009). Giving university students incentives to do homework improves their performance. Journal of Instructional Psychology, 36(3), 219-225.

Rosen, C. (2008). The myth of multitasking. The New Atlantis, 20(1), 105-110. https://www.jstor.org/sta$\underline{\mathrm{ble} / 43152412}$

Saurabh, S., \& Gautam, S. (2019). Modelling and statistical analysis of You'Tube's educational videos: A channel owner's perspective. Computers \& Education, 128, 145-158. https://doi.org/10.1016/j.compedu.2018.09.003

Slemmons, K., Anyanwu, K., Hames, J., Grabski, D., Mlsna, J., Simkins, E., \& Cook, P. (2018). The impact of video length on learning in a middle-level flipped science setting: Implications for diversity inclusion. Journal of Science Education and Technology, 27(5), 469-479. https://doi.org/10.1007/s10956-018-9736-2

Soicher, R. N., \& Becker-Blease, K. A. (2020). Testing the segmentation effect of multimedia learning in a biological system. Journal of Computer Assisted Learning, 36(6), 825-837. https://doi.org/10.1111/jcal.12485

Spanjers, I. A. E., van Gog, T., \& van Merriënboer, J. J. G. (2010). A theoretical analysis of how segmentation of dynamic visualizations optimizes students' learning. Educational Psychology Review, 22(4), 411-423. https://doi.org/10.1007/s10648-010-9135-6

Sweller, J. (1994). Cognitive load theory, learning difficulty, and instructional design. Learning and Instruction, 4(4), 295-312. https://doi.org/10.1016/0959-4752(94)90003-5

Sweller, J. (2010). Element interactivity and intrinsic, extraneous, and germane cognitive load. Educational Psychology Review, 22(2), 123-138. https://doi.org/10.1007/s10648-010-9128-5

Sweller, J., van Merriënboer, J. J. G., \& Paas, F. (1998). Cognitive architecture and instructional design. Educational Psychology Review, 10(3), 251-296. https://doi.org/10.1023/A:1022193728205

Vest, J. (2009, December 02). Six steps to creating high quality video training. http:/ / www.learningsolutionsmag.com/articles/185/six-steps-to-creating-high-quality-video-training

Wittrock, M. C. (1974). Learning as a generative process. Educational Psychologist, 11(2), 87-95. https://doi.org/10.1080/00461527409529129

Wong, A., Leahy, W., Marcus, N., \& Sweller, J. (2012). Cognitive load theory, the transient information effect and e-learning. Learning and Instruction, 22(6), 449-457. https://doi.org/10.1016/j.learninstruc.2012.05.004

Yue, C. L., Bjork, E. L., \& Bjork, R. A. (2013). Reducing verbal redundancy in multimedia learning: An undesired desirable difficulty? Journal of Educational Psychology, 105(2), 266-277. https://doi.org/10.1037/a0031971 


\section{APPENDIX A: QUIZ}

(Correct answers are in italics)

1. Which statement below is NOT supported by the Cone of Experience as originally proposed by Edgar Dale?

a. Direct purposeful experience is the most concrete type of experience.

b. Educational television is more abstract than demonstration.

c. Concrete, direct experience helps students remember.

d. Verbal symbols are an abstract form of experience.

2. Which statement is true about Dale's Cone of Experience?

a. It was intended to show which types of media are best for learning.

b. It was a theoretical framework used to organize the types of media discussed in bis textbook.

c. It included percentages at each level of the pyramid.

d. It is based on empirical research.

3. Which of the statements below is a problem with the popular Cone of Retention that is commonly seen on the Internet?

a. It is attributed to Edgar Dale but is actually a corruption of his work.

b. There is no evidence to support the numbers or percentages it provides.

c. It incorrectly implies that some types of media or experience are inherently better than others in all situations.

d. All of the above.

4. Which of the following is NOT among the arguments educational psychologists make against the Visual-Auditory-Kinesthetic Learning Styles theory?

a. The benefits of targeting teaching to students' learning styles have been shown only in controlled laboratory experiments.

b. There is no evidence showing that catering to students' modality preferences helps their learning.

c. The nature of the subject matter and learner's prior knowledge are likely to have a greater influence on students' learning than whether or not the presentation matches their modality preference.

d. It inappropriately labels students as having only one learning style and implies that they cannot improve their skills in other areas.

5. To teach geography to students who express a preference for the auditory modality, the best approach is probably to

a. Find a way to explain the maps in words.

b. Give students extra support in map reading so they can master the content and improve their skills in understanding images.

c. Only focus on those aspects of geography that are appropriate for auditory learners.

d. Give students an activity that gets them moving around the room.

6. In planning a lesson, a teacher might consider (1) the learners' individual differences; (2) the nature of the lesson topic; (3) students' preference for visual, auditory, or kinesthetic learning. Which of these should the teacher consider?
a. 1 and 2
b. 1 and 3
c. 2 and 3
d. 1,2 , and 3

7. A professor likes to add funny graphics and cartoons to all of the PowerPoint slides he uses in class, because, he says, "it keeps the students awake during lecture." The amusing graphics do not usually have a direct connection to the content of the slide. What would Richard Mayer, author of the Cognitive Theory of Multimedia Learning, most likely say to this professor?

a. The entertaining graphics are helpful because they make use of multimedia technology.

b. The entertaining graphics are helpful, especially for the visual learners in the class.

c. The entertaining graphics are harmful because they can distract students and overload their limited working memory capacity. 
d. The entertaining graphics are harmful because they might overload the memory capacity of students who are auditory learners.

8. Cognitive Theory of Multimedia Learning principles have been proven to hold true in all situations where educational media is used.

a. True

b. False

9. Jane is an experienced teacher supervising a student teacher, Sally. Jane advises Sally to use a variety of different means to help students learn, including lecture, multimedia, small group discussion, and hands-on projects. All of the following statements provide good support for Jane's advice except:

a. Students only remember $20 \%$ of what you tell them in a lecture, so it is best to use techniques farther down on the cone of retention.

b. Students may have different levels of prior knowledge of a subject, and in some cases this has been shown to influence what kinds of activities help them learn.

c. In some situations, text with graphics or audio with graphics can help students learn better than the use of text alone.

d. A given technique or activity may be better suited to some topics or disciplines than others.

10. Which of the following statements is true regarding good teaching practice?

a. One technique should work equally well for all students as long as the students are about the same age.

b. Teachers should remember that every class includes a combination of visual learners, auditory learners, and kinesthetic learners.

c. Hands-on work is always preferable to reading or lecture, since students only remember $10 \%$ of what they read and $20 \%$ or what they hear.

d. Teachers should consider various attributes of their students (e.g., prior knowledge, individual differences) and the nature of the subject they are teaching to find the best way to help students learn.

11. Which of the following statements is true, according to the video lesson you just completed?

a. Teachers should consider students' learning styles (Visual, Auditory, or Kinesthetic) when deciding the best way to present a lesson.

b. Dale's Cone of Experience shows which type of media is best for learning.

c. The Cognitive Theory of Multimedia Learning provides guidance for designers of educational media.

d. All of the above.

\section{APPENDIX B: QUESTIONNAIRE}

Please indicate your level of agreement with the statements below (Scale choices were: strongly disagree, disagree, somewhat disagree, uncertain, somewhat agree, agree, strongly agree)

- I learned a lot from the video lesson.

- The voice narration in the video lesson helped me learn.

- The images in the video lesson helped me learn.

- In general, I like learning from video.

- The length of the video lesson was just right for helping me learn.

- The video lesson was interesting to me.

- In general, I think I learn more from video lessons like this one than I do from face-to-face lectures.

- The video lesson was challenging but not too difficult for me.

- The video lesson was useful to me.

- The video lesson was clear and easy to understand.

- The video lesson was too easy for me.

- In general, I think video lessons like this one and face-to-face lectures are about equal when it comes to helping me learn. 
About how much time did you spend on the video lesson before you took the quiz?

- less than 15 minutes

- 15 - 29 minutes

- 30 - 44 minutes

- 45 minutes or more

Please estimate about how many times you did the following while watching this video lesson: (Options were: $0,1-3,4-6,8-10$, more than 10$)$

- Watched the video from beginning to end without pausing or stopping

- Took a break for 5 or more minutes

- Took a break for less than 5 minutes

- Paused the video to take notes

- Replayed portions of the video

- Sent or replied to a text message

- Multitasked on something other than text messaging

Other than texting, what other multitasking did you do while watching the video? Check all that apply.

- watched another video

- watched television

- played a video game

- read a book or magazine

- read another webpage

- used a social networking site (e.g., Facebook, Twitter, Snapchat, etc.

- talked on the phone

- did homework

- none

- other

Where were you when you completed the video lesson?

- at home/dorm room

- in a campus computer lab

- on campus (e.g., library, student union, etc.) with your own laptop/device

- in an off-campus coffee shop or library

- other

What device did you use to complete the video lesson?

- desktop computer

- laptop computer

- tablet (e.g., iPad, etc.)

- $\quad$ smart phone (e.g., iPhone, Android, etc.)

- other

In general, how would you rate your proficiency with using online learning technology (e.g., course websites, computer, internet, etc.)?

- very low

- somewhat low

- average

- somewhat high

- very high

Please tell us how you felt about this video lesson. What did you like? What didn't you like? Why? 


\section{AUTHORS}

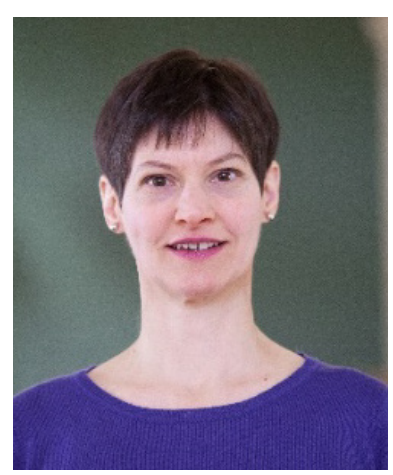

Penny Thompson is an associate professor of educational technology at Oklahoma State University. She received her Ph.D. degree in Educational Psychology and Educational Technology from Michigan State University in 2012. Her research interests include communication and learning in online, blended, and flipped learning environments. She is also interested in all areas where technology and cognition intersect, including both the design of technology to support cognition and the ways immersion in digital technology may or may not be changing habits of mind and attitudes toward learning.

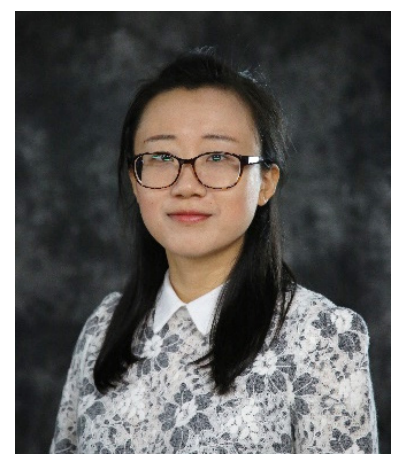

Ying Xiu is an Instructional Designer at University of Illinois UrbanaChampaign. She got her bachelor degree in China and her Ph.D. degree in Educational Technology from Oklahoma State University in May, 2018. Her research interests center on areas where technology facilitates the learning design process to accommodate diverse learners. Her goal is to create student-centered learning environments, improve learning experience, and make learning a little better for everyone.

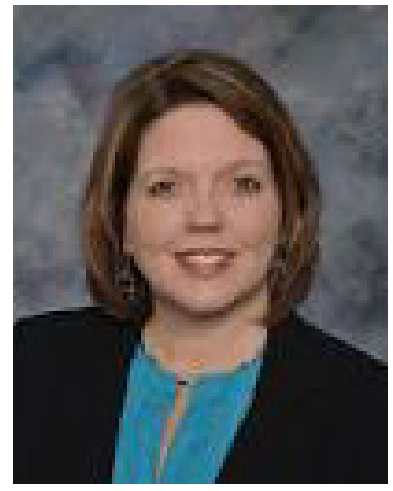

Jessica Tsotsoros is an Assistant Professor in the Rehabilitation Sciences Department at the University of Oklahoma Health Sciences Center. She received her PhD in Educational Technology from Oklahoma State University in 2018 She has practiced as an occupational therapist for twenty years in early intervention, school systems, assistive technology, and mental health. Jessica Tsotsoros has studied power mobility with young children, models of self-determination for adults with visual impairments, and most currently studies a wellness intervention she developed called IHOPE (Integrating Healthy Habits Optimized by Community Participation and Engaged Learning) with special populations.

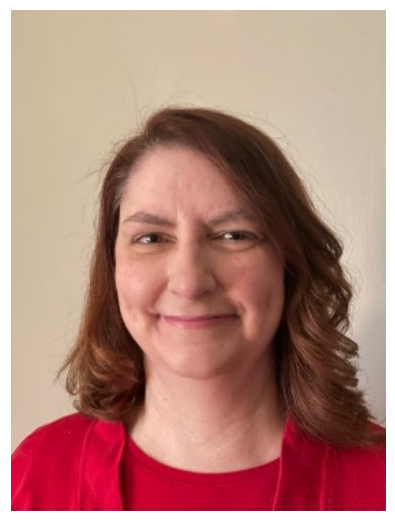

Michelle A. Robertson is currently the program coordinator and instructor in the Library Media in Education program at the University of Central Oklahoma. Her current research focus is school librarians and using social media as an advocacy tool. Michelle is currently working on American Library Association committees that focus on advocacy and technology integration. Education Background is Oklahoma State University, Ph.D., Learning, Design, and Technology, Stillwater, Oklahoma, May 2021, University of Oklahoma, Master's Library and Information Sciences, Norman, OK, July 2005, University of Central Oklahoma, B.S. Elementary Education, Edmond, OK, Spring1997. 